\title{
Implementasi Data Mining menggunakan Algoritma Apriori untuk Menentukan Pola Pembelian Obat di Rumah Sakit
}

\author{
Novita Aulia*1, Indra ${ }^{2}$, Nahya Nur ${ }^{3}$ \\ 1,2,3 Program Studi Teknik Informatika Universitas Sulawesi Barat \\ e-mail: ${ }^{* 1} 98$ novitaaulia@gmail.com, ${ }^{2}$ indra@ unsulbar.ac.id, ${ }^{3}$ nahya.nur@unsulbar.ac.id
}

\begin{abstract}
Abstrak
Data mining merupakan proses untuk mendapatkan informasi yang berguna dari gudang basis data yang berupa ilmu pengetahuan. penelitian ini melakukan analisa data dengan menggunakan data mining dan metode algoritma apriori. Sistem yang dibangun ditujukan untuk pemenuhan dalam penentuan pola pembelian obat dengan menggunakan bahasa pemrograman PHP dan database Mysql pada studi kasus Apotek rumah sakit umum majene. Sistem ini dibangun berdasarkan kebutuhan pengguna yang diperoleh melalui metode wawancara dan studi lapangan dengan jumlah data yang diperoleh yaitu 250 data. Metodologi pengembangan sistem yang digunakan yaitu metode Research and Development $(R \& D)$. yang terdiri Analisis, Desain, Pengkodean dan Pengujian. Hasil pengujian dengan algoritma apriori dan sistem yang dibangun menunjukan hasil yang telah memenuhi kebutuhan dalam penentuan pola pembelian obat di rumah sakit berdasarkan kecenderungan pembelian obat oleh pelanggan.
\end{abstract}

Kata kunci-3-5 Data Mining, Apriori, itemset, pembelian obat

\begin{abstract}
Data mining is a process of obtaining useful information from a database warehouse in the form of knowledge. This study analyzes data using data mining and apriori algorithm methods. The system built is intended to fulfill the determination of drug purchase patterns using the Php programming language and the Mysql database in the case study of the Majene General Hospital Pharmacy. This system is built based on user needs obtained through interviews and field studies with the amount of data obtained is 200 data. The system development methodology used is the Research and Development $(R \& D)$ method. which consists of Analysis, Design, Coding and Testing. The test results with the a priori algorithm and the system built show the results that have met the needs in determining the pattern of drug purchases in hospitals based on the tendency of drug purchases by customers.
\end{abstract}

Keywords-3-5 Data Mining, Apriori, itemset, purchasing

\section{PENDAHULUAN}

Untuk melakukan suatu analisis terhadap data yang akan diolah pada data penjualan obat yang semakin hari semakin banyak, sehingga sebagai arsip dan laporan penjualan obat bagi rumah 
sakit umum majene dan tidak dapat dimanfaatkan rumah sakit umum majene untuk pengembangan dalam penentuan pola pembelian obat. Berdasarkan hasil wawancara yang dilakukan kepada pihak Rumah sakit Umum Majene, yang diwakili oleh kepala ruangan apoteker , ibu Sitti Fatimah S,Farm . Penulis memperoleh kesimpulan bahwa Rumah Sakit Umum Majene memerlukan sistem yang mampu untuk memberikan ilmu teknologi yang mampu membantu untuk memenuhi penyediaan obat yang efektif dan efisien dari penentuan pola pembelian obat, sehingga obat yang paling sering dibeli tersebut dapat menjadi acuan mengembangkan strategi dalam pola penentuan pembelian obat di rumah sakit umum majene.

Pengolahan data untuk memperoleh informasi mengenai pola-pola dapat dilakukan dengan data mining, salah satunya adalah Aturan Asosiasi (Association Rule). Data Mining dipilih karena metodenya dapat mengekstraksi informasi prediktif dalam suatu database yang sangat besar. Aturan Asosiasi dipilih untuk menyelesaikan masalah ini agar dapat mengetahui pola pembelian konsumen dalam membeli barang secara bersamaan. Algoritma Apriori yang merupakan salah satu metode Aturan Asosiasi cocok untuk diterapkan bila terdapat beberapa hubungan item yang ingin dianalisis (Tampubolon dalam artikel Winda dkk, 2017).

Hasil penelitian yang dilakukan oleh Kennedy Tampubolo, Hoga Sargih, dan Bobby Reza penelitian dengan judul "Implementasi Data Mining Algoritma Apriori pada Sistem Persediaan Alat-Alat Kesehatan" dianalisa sejumlah data dengan 30 jenis item, serta ambang batas yang ditentukan adalah minimum support $16 \%$ dan minimum confidence $70 \%$. Dari batasbatas yang diberikan, terbentuk dua aturan asosiasi. Disimpulkan bahwa algoritma apriori cukup efisien dan dapat mempercepat proses pembentukan kecenderungan pola kombinasi itemset.

\section{METODE}

Metode yang digunakan dalam penelitian ini adalah algoritma apriori. Algoritma apriori Merupakan algoritma pengambilan data dengan aturan asosiatif (Association rule) untuk menentukan hubungan asosiatif suatu kombinasi item. Gambar 1 menunjukkan diagram alur dari penentuan pola pembelian obat di rumah sakit dengan menggunakan algoritma apriori.

\section{Analisis Pola Frekuensi Tinggi dengan Algoritma Apriori}

Mencari kombinasi item yang memenuhi syarat minimum dari nilai support dalam basis data. Support adalah nilai persentase kombinasi sebuah item dalam database. Nilai support sebuah item diperoleh dengan menggunakan persamaan (1), sebagai berikut:

$$
\text { Support }(A)=\frac{\text { Jumlah transaksi mengandung } A}{\text { Total transaksi }}
$$

Nilai support dari 2 item diperoleh dengan menggunakan persamaan (2), yaitu:

$$
\begin{aligned}
& \text { Support }(A, B)=P(A \cap B) \\
& \text { Support }(A, B)=\frac{\Sigma \text { transaksi mengandung } A \text { dan } B}{\Sigma \text { transaksi }}
\end{aligned}
$$

\section{Pembentukan Aturan Asosiasi}

Setelah semua pola frekuensi tinggi ditemukan, barulah dicari aturan asosiasi yang memenuhi syarat minimum untuk confidence dengan menghitung confidence aturan asosiatif A $\cup$ B. Confidence adalah kuatnya hubungan keterkaitan antar item dalam database. Nilai confidence dari aturan $\mathrm{A} \cup \mathrm{B}$ diperoleh dengan formula (3) berikut.

$$
\text { Confidence }=P(B \mid A)=\frac{\Sigma \text { transaksi mengandung Adan } B}{\Sigma \text { transaksi }}
$$


Untuk menentukan aturan asosiasi yang akan dipilih maka harus diurutkan berdasarkan Support $\times$ Confidence. Aturan diambil sebanyak $n$ aturan yang memiliki hasil terbesar.

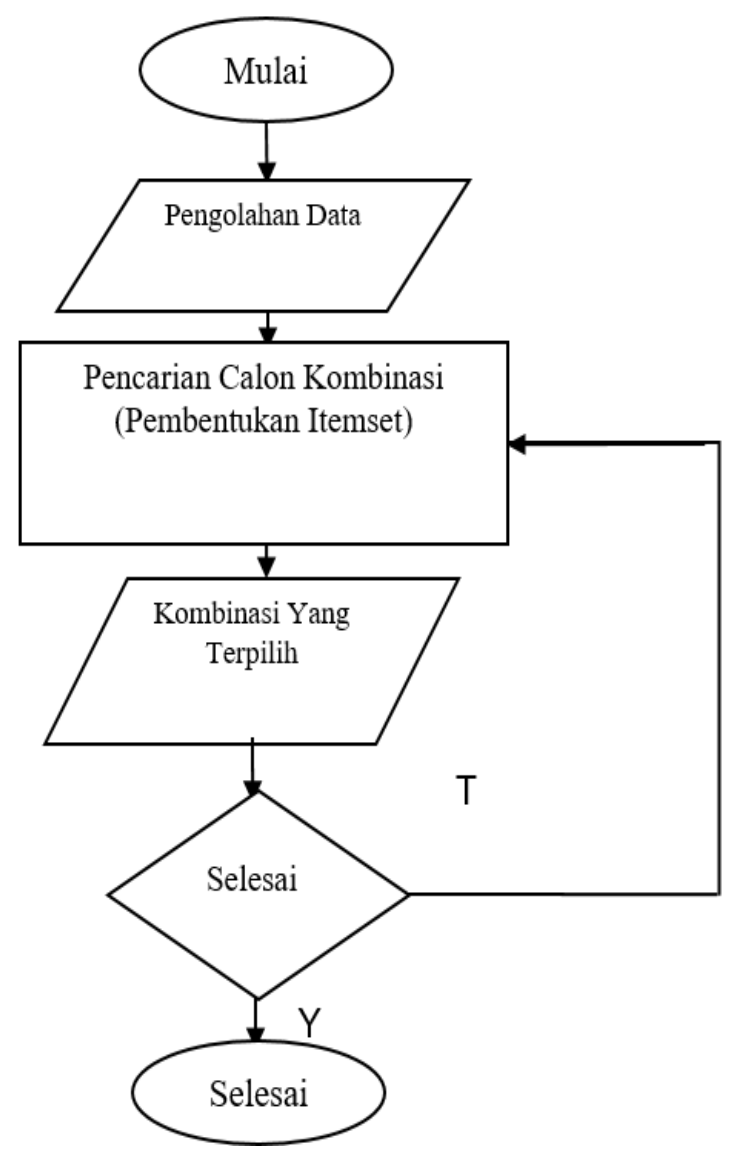

Gambar 1 Diagram Alur Penentuan pola pembelian obat di rumah sakit

\section{HASIL DAN PEMBAHASAN}

Berdasarkan hasil wawancara dan observasi yang sudah dilakukan, peneliti memperoleh data transaksi penjualan Apotek rumah sakit yang berupa buku catatan / folio. Data transaksi tersebut kemudian akan diinputkan ke excel agar bisa dianalisis. Berdasarkan data yang didapat dari transaksi penjualan maka peneliti akan menampilkan data transaksi penjualan obat Apotek rumah sakit yang sudah diinputkan ke excel dengan 250 transaksi penjualan obat dengan menggunakan BPJS. Dari beberapa data yang diuji di sistem didapatkan data dengan jumlah 90 data yang lolos pada tanggal 03 Juni - 15 Desember 2020. dilihat pada tabel 1. 
Tabel 1 Sample Transaksi Penjualan Obat Bulan Juni-Desember 2020

\begin{tabular}{|c|c|}
\hline No & Obat Yang Dibeli \\
\hline 1 & $\begin{array}{l}\text { Sureplus Infusion Set Adult, IV Cath Pro 20G, Nacl 0,9\% } 500 \mathrm{Ml} \mathrm{Inf} \text {, } \\
\text { Paracetamol Inf , Moxifloxacin Hcl 400 Ml Inf ,Remedi Dispo } 1 \text { CC ,Ibuprofen } \\
\text { Tab } 400 \mathrm{Mg} \text {, Ambroxol Tab } 30 \mathrm{Mg} \text {, Azithromycin } 500 \mathrm{Mg}\end{array}$ \\
\hline 2 & $\begin{array}{l}\text { Sureplus Infusion Set, Ringer Lactat } 500 \mathrm{Ml} \text {, Odansetron Inj } 4 \mathrm{Mg} \text {, Ranitidin Inj } \\
\text {,Paracetamol Inf, Remedi Dispo } 3 \mathrm{CC} \text {, Remedi Dispo } 5 \mathrm{CC} \text {, Remedi Dispo } 10 \\
\text { CC , IV Cath Pro 20G, OdansetronTab } 8 \mathrm{Mg} \text {, Ranitidi Tab } 150 \mathrm{Mg} \text {, Biocombin } \\
\text { Tab. }\end{array}$ \\
\hline 3 & $\begin{array}{l}\text { Ringer Lactat } 500 \mathrm{Ml} \text {, Nacl 0,9\% } 500 \mathrm{Ml} \text { Inf, D5\%, IV Cath Pro } 18 \mathrm{G} \text {, Sureplus } \\
\text { Infusion Set Adult, Sureplus Infusion Set, Urine Bag Steril } 2 \mathrm{Lt} \text {, Chateter } 16 \text {, } \\
\text { Remedi Dispo } 10 \mathrm{CC} \text {, Remedi Dispo } 3 \mathrm{CC} \text {, Remedi Dispo } 1 \mathrm{CC} \text {, Bisturi } 23 \text {, } \\
\text { Vicryl 1/0, Catgut Chromic } 2 / 0 \mathrm{Hr} 37 \text {, Vicryl 2/0, Vicryl 3/0, Dexametason Inj }\end{array}$ \\
\hline 4 & $\begin{array}{l}\text { Ringer Lactat } 500 \mathrm{Ml} \text {, Nacl 0,9\% } 500 \mathrm{Ml} \text {, Sureplus Infusion Set, IV Cath Pro } \\
18 \mathrm{G} \text {, Sureplus Infusion Set Adult, Urine Bag Steril } 2 \mathrm{Lt} \text {, Chateter } 16 \text {, Aquadest } \\
25 \mathrm{Ml} \text {, Remedi Dispo } 3 \mathrm{CC} \text {, Remedi Dispo } 10 \mathrm{CC} \text {,Ceftriaxone Inj , } \\
\text { Phytomenadion Inj } 2 \mathrm{Mg} / \mathrm{Ml} \text {, }\end{array}$ \\
\hline 5 & $\begin{array}{l}\text { Amoxicylin Tab 500 Mg, Asam Mefenamat Tab 500 Mg,Biocombin Tab, Ringer } \\
\text { Lactat } 500 \mathrm{Ml} \text {, D5\% , Aquadest } 25 \mathrm{Ml} \text {, Remedi Dispo } 3 \text { CC, Remedi Dispo } 10 \\
\text { CC ,Ceftriaxone Inj, Ketorolac Inj 3\%, Paracetamol Inf }\end{array}$ \\
\hline
\end{tabular}

Data pada tabel 1 adalah bentuk transaksi data penjualan ( data obat keluar ) real terdiri atas attribute nomor transaksi dan nama obat.

\subsection{Pembentukan Itemset}

Proses pembentukan nilai support untuk 1 itemset dengan jumlah minimum support $=$ 20\%. Perhitungan support dilakukan berdasarkan persamaan 1

$$
\text { Support }=\frac{57}{90} \times 100 \%=63,33 \%
$$

Tabel 2 Nilai Support Untuk 1 Itemset

\begin{tabular}{cccc}
\hline No & Item & Jumlah & Support \% \\
\hline 1 & M001 & 57 & 63,33 \\
\hline 2 & M002 & 52 & 57,78 \\
\hline 3 & M003 & 24 & 26,67 \\
\hline 4 & M004 & 54 & 60,00 \\
\hline 5 & M005 & 56 & 62,22 \\
\hline 6 & M006 & 32 & 35,56 \\
\hline 7 & M007 & 26 & 28,89 \\
\hline 8 & M008 & 45 & 50,00 \\
\hline 9 & M015 & 34 & 37,78 \\
\hline 10 & M016 & 44 & 48,89 \\
\hline 11 & M018 & 23 & 25,56 \\
\hline 12 & M021 & 37 & 41,11 \\
\hline 13 & M027 & 44 & 48,89 \\
\hline 14 & M049 & 24 & 26,67 \\
\hline
\end{tabular}




\subsection{Kombinasi 2 Itemset}

Proses pembentukan nilai support untuk 2 itemset dengan jumlah minimum support $=20 \%$ dapat diselesaikan dengan persamaan 2.2

$$
\text { Support }=\frac{45}{90} \times 100 \%=50,00 \%
$$

Tabel 3 Nilai Support Untuk 2 Itemset

\begin{tabular}{|c|c|c|c|}
\hline No & Item & Jumlah & Support \% \\
\hline 1 & M001,M002 & 45 & 50,00 \\
\hline 2 & M001,M003 & 20 & 22,22 \\
\hline 3 & M001,M004 & 34 & 37,78 \\
\hline 4 & M001,M005 & 36 & 40,00 \\
\hline 5 & M001,M006 & 20 & 22,22 \\
\hline 6 & M001,M008 & 33 & 36,67 \\
\hline 7 & M001,M015 & 23 & 25,56 \\
\hline 8 & M001,M016 & 37 & 41,11 \\
\hline 9 & M001,M021 & 30 & 33,33 \\
\hline 10 & M001,M027 & 23 & 25,56 \\
\hline 11 & M002,M004 & 28 & 31,11 \\
\hline 12 & M002,M005 & 38 & 42,22 \\
\hline 13 & M002,M006 & 20 & 22,22 \\
\hline 14 & M002,M008 & 24 & 26,67 \\
\hline 15 & M002,M015 & 21 & 23,33 \\
\hline 16 & M002,M016 & 39 & 43,33 \\
\hline 17 & M002,M021 & 34 & 37,78 \\
\hline 18 & M002,M027 & 24 & 26,67 \\
\hline 19 & M004,M005 & 35 & 38,89 \\
\hline 20 & M004,M008 & 37 & 41,11 \\
\hline 21 & M004,M016 & 21 & 23,33 \\
\hline 22 & M004,M027 & 38 & 42,22 \\
\hline 23 & M005,M006 & 24 & 26,67 \\
\hline 24 & M005,M008 & 28 & 31,11 \\
\hline 25 & M005,M015 & 22 & 24,44 \\
\hline 26 & M005,M016 & 32 & 35,56 \\
\hline 27 & M005,M021 & 26 & 28,89 \\
\hline 28 & M005,M027 & 24 & 26,67 \\
\hline 29 & M006,M015 & 24 & 26,67 \\
\hline 30 & M008,M016 & 20 & 22,22 \\
\hline 31 & M008,M027 & 21 & 23,33 \\
\hline 32 & M015,M016 & 23 & 25,56 \\
\hline 33 & M016,M021 & 37 & 41,11 \\
\hline 34 & M016,M027 & 21 & 23,33 \\
\hline
\end{tabular}


3.3 Kombinasi 3 Itemset

Proses pembentukan nilai support untuk 3 itemset dengan jumlah minimum support $=20 \%$ dapat diselesaikan dengan persamaan 2

$$
\text { Support }=\frac{34}{90} \times 100 \%=37,78 \%
$$

Tabel 4 Nilai Minimal Support 20\% Untuk 3 Itemset

\begin{tabular}{|c|c|c|c|}
\hline No & Item & Jumlah & Support \% \\
\hline 1 & M001,M002,M004 & 25 & 27,78 \\
\hline 2 & M001,M002,M005 & 31 & 34,44 \\
\hline 3 & M001,M002,M008 & 24 & 26,67 \\
\hline 4 & M001, M002,M016 & 33 & 36,67 \\
\hline 5 & M001, M002,M021 & 28 & 31,11 \\
\hline 6 & M001, M002,M027 & 21 & 23,33 \\
\hline 7 & M004,M002,M005 & 20 & 22,22 \\
\hline 8 & M001,M004,M008 & 25 & 27,78 \\
\hline 9 & M001,M004,M027 & 22 & 24,44 \\
\hline 10 & M004,M002,M027 & 23 & 25,56 \\
\hline 11 & M001,M004,M005 & 21 & 23,33 \\
\hline 12 & M001,M005,M016 & 25 & 27,78 \\
\hline 13 & M005,M002,M016 & 29 & 32,22 \\
\hline 14 & M005,M002,M021 & 25 & 27,78 \\
\hline 15 & M001,M008,M016 & 20 & 22,22 \\
\hline 16 & M015,M002,M016 & 21 & 23,33 \\
\hline 17 & M001,M016,M021 & 30 & 33,33 \\
\hline 18 & M016,M002,M021 & 34 & 37,78 \\
\hline 19 & M016,M002,M027 & 20 & 22,22 \\
\hline 20 & M005,M004,M008 & 22 & 24,44 \\
\hline 21 & M005,M004,M027 & 23 & 25,56 \\
\hline 22 & M008,M004,M027 & 21 & 23,33 \\
\hline
\end{tabular}




\begin{tabular}{llcl}
\hline No & Item & Jumlah & Support \% \\
\hline 23 & M016,M004,M027 & 20 & 22,22 \\
\hline 24 & M015,M005,M016 & 20 & 22,22 \\
\hline 25 & M016,M005,M021 & 26 & 28,89
\end{tabular}

Untuk jumlah item yang dibeli sekaligus yaitu Sureplus Infusion Set Adult, IV Cath pro $20 \mathrm{G}$ pada itemset 2 ada 45 transaksi, dan itemset 1 pada Sureplus Infusion Set Adult ada 57 . Nilai confidence dari $\mathrm{A} \rightarrow \mathrm{B}$ diperoleh dengan persamaan 3

$$
\text { Confidence }=\frac{45}{57} \times 100 \%=78,9 \%
$$

Perhitungan confidence berdasarkan minimal support dan minimal confidence yang telah ditentukan dapat dilihat pada tabel 5 :

Tabel 5 Nilai Confidence dari itemset

\begin{tabular}{|c|c|c|c|}
\hline No & Item & Support \% & Confidence $\%$ \\
\hline 1 & M001,M002 & 50,00 & 78,9 \\
\hline 2 & M001,M003 & 22,22 & 35,08 \\
\hline 3 & M001,M004 & 37,78 & 59,64 \\
\hline 4 & M001,M005 & 40,00 & 63,15 \\
\hline 5 & M001,M006 & 22,22 & 35,08 \\
\hline 6 & M001,M008 & 36,67 & 57,89 \\
\hline 7 & M001,M015 & 25,56 & 40,35 \\
\hline 8 & M001,M016 & 41,11 & 64,91 \\
\hline 9 & M001,M021 & 33,33 & 38,59 \\
\hline 10 & M001,M027 & 25,56 & 52,63 \\
\hline 11 & M002,M004 & 31,11 & 40,35 \\
\hline 12 & M002,M005 & 42,22 & 53,84 \\
\hline 13 & M002,M006 & 22,22 & 73,07 \\
\hline 14 & M002,M008 & 26,67 & 38,46 \\
\hline 15 & M002,M015 & 23,33 & 46,15 \\
\hline 16 & M002,M016 & 43,33 & 40,38 \\
\hline 17 & M002,M021 & 37,78 & 75 \\
\hline 18 & M002,M027 & 26,67 & 65,38 \\
\hline 19 & M004,M005 & 38,89 & 64,81 \\
\hline 20 & M004,M008 & 41,11 & 68,51 \\
\hline 21 & M004,M016 & 23,33 & 38,89 \\
\hline 22 & M004,M027 & 42,22 & 70,37 \\
\hline 23 & M005,M006 & 26,67 & 42,85 \\
\hline 24 & M005,M008 & 31,11 & 50 \\
\hline 25 & M005,M015 & 24,44 & 39,28 \\
\hline 26 & M005,M016 & 35,56 & 57,14 \\
\hline 27 & M005,M021 & 28,89 & 46,42 \\
\hline 28 & M005,M027 & 26,67 & 42,85 \\
\hline 29 & M006,M015 & 26,67 & 75 \\
\hline 30 & M008,M016 & 22,22 & 44,44 \\
\hline 31 & M008,M027 & 23,33 & 46,67 \\
\hline
\end{tabular}




\begin{tabular}{llll}
\hline No & \multicolumn{1}{c}{ Item } & Support $\%$ & Confidence\% \\
\hline 32 & M015,M016 & 25,56 & 67,64 \\
\hline 33 & M016,M021 & 41,11 & 84,09 \\
\hline 34 & M016,M027 & 23,33 & 47,72 \\
\hline 35 & M001,M002,M004 & 27,78 & 43,86 \\
\hline 36 & M001,M002,M005 & 34,44 & 54,39 \\
\hline 37 & M001,M002,M008 & 26,67 & 42,10 \\
\hline 38 & M001, M002,M016 & 36,67 & 57,89 \\
\hline 39 & M001, M002,M021 & 31,11 & 49,18 \\
\hline 40 & M001, M002,M027 & 23,33 & 36,86 \\
\hline 41 & M004,M002,M005 & 22,22 & 37,07 \\
\hline 42 & M001,M004,M008 & 27,78 & 43,89 \\
\hline 43 & M001,M004,M027 & 24,44 & 38,59 \\
\hline 44 & M004,M002,M027 & 25,56 & 42,59 \\
\hline 45 & M001,M004,M005 & 23,33 & 36,86 \\
\hline 46 & M001,M005,M016 & 27,78 & 43,89 \\
\hline 47 & M005,M002,M016 & 32,22 & 51,78 \\
\hline 48 & M005,M002,M021 & 27,78 & 44,69 \\
\hline 49 & M001,M008,M016 & 22,22 & 35,09 \\
\hline 50 & M015,M002,M016 & 23,33 & 61,78 \\
\hline 51 & M001,M016,M021 & 33,33 & 52,69 \\
\hline 52 & M016,M002,M021 & 37,78 & 72,27 \\
\hline 53 & M016,M002,M027 & 22,22 & 45,45 \\
\hline 54 & M005,M004,M008 & 24,44 & 39,28 \\
\hline 55 & M005,M004,M027 & 25,56 & 41,08 \\
\hline 56 & M008,M004,M027 & 23,33 & 46,67 \\
\hline 57 & M016,M004,M027 & 22,22 & 55,45 \\
\hline 58 & M015,M005,M016 & 22,22 & 59,09 \\
\hline 59 & M016,M005,M021 & 28,89 &
\end{tabular}

Minimal confidence yang ditentukan adalah 50\% jadi kombinasi dari 2 itemset yang tidak memenuhi minimal confidence akan dihilangkan, dapat dilihat seperti tabel 6:

Tabel 6 Nilai Confidence dan support yang memenuhi

\begin{tabular}{llll}
\hline No & Item & Support \% & Confidence\% \\
\hline 1 & M001,M002 & 50,00 & 78,9 \\
\hline 2 & M001,M004 & 37,78 & 59,64 \\
\hline 3 & M001,M005 & 40,00 & 63,15 \\
\hline 4 & M001,M008 & 36,67 & 57,89 \\
\hline 5 & M001,M016 & 41,11 & 64,91 \\
\hline 6 & M001,M027 & 25,56 & 52,63 \\
\hline 7 & M002,M005 & 42,22 & 53,84 \\
\hline
\end{tabular}




\begin{tabular}{|c|c|c|c|}
\hline No & Item & Support \% & Confidence $\%$ \\
\hline 8 & M002,M006 & 22,22 & 73,07 \\
\hline 9 & M002,M021 & 37,78 & 75 \\
\hline 10 & M002,M027 & 26,67 & 65,38 \\
\hline 11 & M004,M005 & 38,89 & 64,81 \\
\hline 12 & M004,M008 & 41,11 & 68,51 \\
\hline 13 & M004,M027 & 42,22 & 70,37 \\
\hline 14 & M005,M008 & 31,11 & 50 \\
\hline 15 & M005,M016 & 35,56 & 57,14 \\
\hline 16 & M006,M015 & 26,67 & 75 \\
\hline 17 & M015,M016 & 25,56 & 67,64 \\
\hline 18 & M016,M021 & 41,11 & 84,09 \\
\hline 19 & M001,M002,M005 & 34,44 & 54,39 \\
\hline 20 & M001, M002,M016 & 36,67 & 57,89 \\
\hline 21 & M005,M002,M016 & 32,22 & 51,78 \\
\hline 22 & M015,M002,M016 & 23,33 & 61,78 \\
\hline 23 & M001,M016,M021 & 33,33 & 52,69 \\
\hline 24 & M016,M002,M021 & 37,78 & 72,27 \\
\hline 25 & M015,M005,M016 & 22,22 & 58,89 \\
\hline 26 & M016,M005,M021 & 28,89 & 59,09 \\
\hline
\end{tabular}

\subsection{Aturan Asosiasi Final}

Adapun aturan asosiasi akhir yang diperoleh dari kombinasi jumlah item set adalah sebagai berikut:

1. Jika konsumen membeli Sureplus Infusion Set Adult, maka konsumen juga akan membeli IV Cath Pro 20 G, Confidence 78,9\%

2. Jika konsumen membeli Sureplus Infusion Set Adult, maka konsumen juga akan membeli Remedi Dispo 10 CC, Confidence 59,64\%

3. Jika konsumen membeli Sureplus Infusion Set Adult, maka konsumen juga akan membeli Remedi Dispo 1 CC, Confidence 63,15\%

4. Jika konsumen membeli Sureplus Infusion Set Adult, maka konsumen juga akan membeli Remedi Dispo 3 CC, Confidence 57,89\%

5. Jika konsumen membeli Sureplus Infusion Set Adult, maka konsumen juga akan membeli Nacl 0, Confidence 64,91\% 
6. Jika konsumen membeli Sureplus Infusion Set Adult, maka konsumen juga akan membeli Aquadest, Confidence 52,63\%

7. Jika konsumen membeli IV Cath Pro 20 G, maka konsumen juga akan membeli Remedi Dispo 1 CC, Confidence 53,84\%

8. Jika konsumen membeli IV Cath Pro $20 \mathrm{G}$, maka konsumen juga akan membeli Ketorolac Inj 3\%, Confidence 73,07\%

9. Jika konsumen membeli IV Cath Pro $20 \mathrm{G}$, maka konsumen juga akan membeli 9\% 500 Ml, Confidence $75 \%$

10. Jika konsumen membeli IV Cath Pro $20 \mathrm{G}$, maka konsumen juga akan membeli Aquadest, Confidence 65,38\%

11. Jika konsumen membeli Remedi Dispo $10 \mathrm{CC}$, maka konsumen juga akan membeli Remedi Dispo 1 CC, Confidence 64,81\%

12. Jika konsumen membeli Remedi Dispo $10 \mathrm{CC}$, maka konsumen juga akan membeli Remedi Dispo 3 CC, Confidence 68,51\%

13. Jika konsumen membeli Remedi Dispo $10 \mathrm{CC}$, maka konsumen juga akan membeli Aquadest, Confidence 70,37\%

14. Jika konsumen membeli Remedi Dispo $1 \mathrm{CC}$, maka konsumen juga akan membeli Remedi Dispo 3 CC, Confidence 50\%

15. Jika konsumen membeli Remedi Dispo $1 \mathrm{CC}$, maka konsumen juga akan membeli Nacl 0, Confidence $57,14 \%$

16. Jika konsumen membeli Ketorolac , maka konsumen juga akan membeli Ranitidin, Confidence $75 \%$

17. Jika konsumen membeli Ranitidin , maka konsumen juga akan membeli Nacl 0 , Confidence $67,64 \%$

18. Jika konsumen membeli Nacl 0, maka konsumen juga akan membeli $9 \% 500 \mathrm{Ml}$, Confidence $84,09 \%$

19. Jika konsumen membeli Sureplus Infusion Set Adult, IV Cath Pro $20 \mathrm{G}$ maka konsumen juga akan membeli Remedi Dispo 1 CC, Confidence 54,39\%

20. Jika konsumen membeli Sureplus Infusion Set Adult, IV Cath Pro $20 \mathrm{G}$ maka konsumen juga akan membeli Nacl 0, Confidence 57,89\%

21. Jika konsumen membeli Remedi Dispo 1 CC, IV Cath Pro 20 G maka konsumen juga akan membeli Nacl 0, Confidence 51,78\%

22. Jika konsumen membeli Ranitidin Inj, IV Cath Pro $20 \mathrm{G}$ maka konsumen juga akan membeli Nacl 0, Confidence 61,78\%

23. Jika konsumen membeli Sureplus Infusion Set Adult, Nacl 0 maka konsumen juga akan membeli $9 \% 500 \mathrm{Ml}$, Confidence 52,69\%

24. Jika konsumen membeli Nacl 0, IV Cath Pro $20 \mathrm{G}$ maka konsumen juga akan membeli 9\% $500 \mathrm{Ml}$, Confidence $72,27 \%$

25. Jika konsumen membeli Ranitidin Inj, Remedi Dispo $1 \mathrm{CC}$ maka konsumen juga akan membeli Nacl 0, Confidence 58,89\%

26. Jika konsumen membeli Nacl 0, Remedi Dispo $1 \mathrm{CC}$ maka konsumen juga akan membeli 9\% $500 \mathrm{Ml}$, Confidence 59,09\%

Berdasarkan rule yang ada Confidence 78,9\% dikarenakan pada saat Sureplus Infusion Set Adult habis maka IV Cath Pro $20 \mathrm{G}$ juga akan habis dikarenakan pada saat konsumen membeli obat tersebut pastinya kedua obat tersebut harus di beli. 


\section{KESIMPULAN}

Berdasarkan hasil pengujian yang telah dilakukan dapat disimpulkan bahwa system implementasi pola pembelian obat di rumah sakit yang telah dibuat sudah memenuhi harapan untuk bisa membantu dalam menentukan obat mana yang paling sering terjual di apotik rumah sakit dengan mengimplementasikan metode algoritma Apriori sebagai perhitungan dengan data yang sudah ada ditentukan bahwa oabat yang paling sering terjual adalah Sureplus Infusion Set Adult ,IV Cath Pro 20 G, Nacl 0 , Remedi Dispo 3 CC, Remedi Dispo 10 CC, Remedi Dispo 1 CC, Aquadest, Ranitidin, Ketorolac inj dan Ringer Lactat 500 Ml.. Dimana hasil pengujian black box dapat disimpulkan bahwa sistem sudah dapat memenuhi persyaratan fungsional atau berjalan dengan baik, dan menghasilkan pola pembelian obat di rumah sakit. Para peneliti selanjutnya yang ingin mengembangkan Implementasi Data Mining tentang penentuan pola pembelian obat di rumah sakit dapat dilakukan dengan menambahkan data dengan menggunakan metode algoritma Apriori atau dengan menggunakan metode lain di seluruh bagian perhitungan Apriori. Sehingga akan menghasilkan keputusan yang lebih akurat lagi dan dapat dipergunakan sebagai referensi bagi peneliti selanjutnya.

\section{REFERENSI}

[1] Al Syahdan, S., \& Sindar, A. (2018). Data Mining Penjualan Produk Dengan Metode Apriori Pada Indomaret Galang Kota. Jurnal Nasional Komputasi dan Teknologi Informasi, 1(2), 268080

[2] Hermawati, F. A. (2013). Data Mining. Yogyakarta: Penerbit Andi.

[3] Hakim, M. W. 2014. PengembanganAplikasiPenilaianMatematika SMA BerdasarkanKurikulum 2013 dengan Microsoft Excel. Skripsi. Surabaya: Universitas Islam Negeri SunanAmpel

[4] usrini, \& Emha Taufik Luthfi. (2009). Algoritma Data Mining, Penerbit Andi, Yogyakarta

[5] Kennedi Tampubolon, Hoga Saragih, \& Bobby Reza. (2013).Implementasi Data Mining Agoritma Apriori Pada Sistem Persediaan Alat-Alat Kesehatan. Informasi dan Teknologi Ilmiah (INTI)Volume : I, Nomor : 1.

[6] Nursikuwagus, A. (2020). Implementasi algoritma apriori untuk analisis penjualan dengan berbasis web.

[7] Prasetyo, Eko. 2012. Data Mining Konsep Dan Aplikasi Menggunakan Matlab, Ed.1, Andi Offset,Yogyakarta.

[8] Pane, D. K. (2013). Implementasi Data Mining Pada Penjualan Produk Elektronik Dengan Algoritma Apriori (Studi Kasus : Kreditplus). Pelita Informatika Budi Darma.

[9] Purnia, D. S., \& Warnilah, A. I. (2017). Implementasi Data Mining Pada Penjualan Kacamata Menggunakan Algoritma Apriori. IJCIT (Indonesian Journal on Computer and Information Technology), 2(2).

[10] Sikumbang, E. D. (2018). Penerapan Data Mining Penjualan Sepatu Menggunakan Metode Algoritma Apriori. Jurnal Teknik Komputer, 4(1), 156-161. 